\title{
Current research on cell death mechanisms
}

\author{
Hermann M. Bolt · Hassan Ahmed · Seddik Hammad
}

Published online: 14 November 2014

(C) Springer-Verlag Berlin Heidelberg 2014

Cell death is one of the key events by which chemicals cause adverse effects. Of course, the relevance of cell death for in vivo toxicity is organ and tissue dependent. For example, hepatotoxic chemicals often reach cytotoxic levels in vivo; adverse effects, such as fibrosis (Godoy et al. 2013; Nussler et al. 2014), are usually observed after cell killing. On the other hand, adverse effects in other organs, e.g., the central nervous system, may be caused by noncytotoxic concentrations by compromising connectivity of neurons, receptor expression, or neurotransmitter metabolism (van Thriel et al. 2012; Weng et al. 2014; Balmer et al. 2014; Sisnaiske et al. 2014; Waldmann et al. 2014; Krug et al. 2013). Although it is clear that adverse effects can also occur without cell killing by disturbed cell functions, chemicals always have to be considered as critical when close to cytotoxic concentrations are reached in vivo. Therefore, it is not surprising that cell death research and research on factors modifying susceptibility to cell death represent cutting edge topics in toxicology (Indran et al. 2011; Jazirehi et al. 2011; Jiang et al. 1999; Galán et al. 2001; Ambrosio et al. 1993; Aoki et al. 2002; Ashkenazi and Dixit 1998; Barnhart et al. 2003). The most intensively

H. M. Bolt

Leibniz Research Centre for Working Environment and Human

Factors (IfADo), Ardeystrasse 67, 44139 Dortmund, Germany

H. Ahmed

Department of Physiology, Faculty of Veterinary Medicine, South

Valley University, Qena, Egypt

S. Hammad $(\square)$

Department of Forensic Medicine and Veterinary Toxicology, Faculty of Veterinary Medicine, South Valley University, Qena, Egypt

e-mail: Seddik.hammad@vet.svu.edu.eg; el-kariem@ifado.de studied and perhaps also most relevant cell death mechanism is apoptosis (Alster et al. 2014; Lopez et al. 2014; Bezler et al. 2012; Ilowski et al. 2011; Godoy et al. 2009). Its morphological features have already been described by Fleming in 1885 as a series of events that include chromatin condensation, membrane surface blebbing, and the breakdown of the cell into apoptotic bodies (Matés et al. 2012; D'Emilio et al. 2010). This strictly defined sequence of events guaranties that cells die in an orderly way in contrast to the chaotic cell death of necrosis (Matés et al. 2008, 2012; Wyllie 2010; Yoo et al. 2009; Hammad et al. 2014; Gabai et al. 2000). This process allows the removal of cells from tissues without inflammation. It plays an important role in embryonic development of organisms and in tissue homeostasis (Morita et al. 2001). When chemicals interfere with the control mechanisms of apoptosis, they may cause cell death at very low concentrations. Therefore, the control mechanisms of pro- and anti-apoptotic factors and their disturbance by chemicals traditionally represent an intensively studied field in toxicology. To give our readers an overview, we summarize key messages from articles about cell death mechanisms published since 2012 (Table 1). 
Table 1 Key messages of publications in the field of cell death mechanisms published in Archives of Toxicology since 2012

Key message

Disruptions of $\mathrm{ROS} / \mathrm{Ca}^{2+}$ play a key role in modulating adaptive and death pathways in response to $\mathrm{Cd}^{2+}$ exposure

The hepatotoxic mode of action of amphetamines in combination does not deviate from the individual mechanisms

Caffeic acid causes apoptosis b phospholipase c dependent release of $\mathrm{Ca}^{2+}$ from the endoplasmic reticulum

Autophagy mitigates apoptosis through modulating PI3K/Akt, ERK and JNK signaling

This review gives an overview of mitochondria-dependent and mitochondria-independent pathways of apoptosis

The cereal mycotoxin zearalenone induces suicidal erythrocyte death by an increase in cytosolic calcium

The neurotoxicant trimethyltin chloride induces apoptosis by disturbing the balance between NF-kappa B and MAPKs

The anti-tubulin agent DPQZ induces apoptosis by RAS/Raf inhibition

Micro RNA-210 targets Bcl-2 and induces apoptosis in neuroblastoma cells

Beta-ionone initiates apoptosis via PI3K-Akt

$\mathrm{ABCC} 1$ causes resistance to arsenic compounds

The valproic acid (VPA) analog, (S)-2-pentyl-4-pentynoic acid, is more apoptogenic than valproic acid

Cytotoxicity of $\mathrm{TiO}_{2}$ nanoparticles is size dependent

Paraquat activates the Nrf2/HO-1 pathway in the substantia nigra, whereas tert-butylhydroquinone conferees neuroprotection

Nanosized copper oxide induces apoptosis by oxidative stress in podocytes

This comprehensive review uptakes the role of oxidative stress in apoptosis and cancer

The widely used herbicide paraquat induces apoptosis in alveolar epithelial cells by dysregulation of the Nrf-2 pathway

Endosomes and lysosomes play a key role in thallium induced apoptosis

Arsenic induces apoptosis in myoblasts via reactive oxygen induced ER stress.

Intracellular calcium but not the level of reactive oxygen species controls rotenone induced apoptosis in neuronal cells

Melatonin prevents nephrotoxicity by restoration of antioxidative enzymes, and antagonization of iNOS and NF-

Kappa B

Barium inhibits arsenic by modulating JNK 1/2, caspase 3, NF-Kappa B and XIAP

The shape of hydroxyapatite nanoparticles influences cytotoxicity

The anticancer agent polyphyllin D causes apoptosis in erythrocytes by membrane permeabilization and increased intracellular $\mathrm{Ca}^{2+}$

Polymorphisms of glutathione S-transferase omega 1-1 may increase the risk of apoptosis related diseases in humans exposed to arsenicals

Needle and plate-shaped nanosized hydroxyl-apatite are more cytotoxic than corresponding spherical or rodshaped nanoparticles

The fungicide ziram induces apoptosis in human T-lymphocytes by the mitochondrial/cytochrome c pathway

Apoptosis induced by the Alternaria mycotoxin alternariol in murine hepatoma cells is Ah receptor dependent

Dimethoxycurcumin, a synthetic analog of curcumin includes S-phase arrest and apoptosis in breast cancer cells (MCF 7)

Stress activated protein kinases can operate independently of P53 by a pathway downstream of caspases

Cocaine induces apoptosis in cultivated proximal tubular epithelial cells of the kidney

Inhibition of autophagy protects from pyocyanin induced cell death

The flavonoid fisetin induces apoptosis in Hela cells by the caspase-8/caspase-3 pathway

2,5-Hexanedione, the main active metabolite of $n$-hexane, induces apoptosis in human ovarian granulosa cells through Bcl-2, Bax and caspase-3 pathways

Salubrinal, an inhibitor of eIF2 alpha dephosphorylation, protects human renal proximal tubular cells from $\mathrm{CdCl} 2$ induced apoptosis

Cerium chloride induces apoptosis in mouse hepatocytes
References

Thévenod and Lee (2013)

Dias da Silva et al. (2013)

Chang et al. (2013)

Hsieh et al. (2013)

Sinha et al. (2013)

Jilani and Lang (2013)

Qing et al. (2013)

Hour et al. (2013)

Chio et al. (2013)

Liu et al. (2013)

Xu et al. (2013b)

Ivanova et al. (2013)

Xiong et al. (2013)

Li et al. (2012a)

Xu et al. (2013a)

Matés et al. (2012)

Chen et al. (2012)

Hanzel et al. (2012)

Yen et al. (2012)

Swarnkar et al. (2012)

Lee et al. (2012)

Yajima et al. (2012)

An et al. (2012)

Gao et al. (2012)

Escobar-García et al. (2012)

Zhao et al. (2013)

Li et al. (2012b)

Schreck et al. (2012)

Kunwar et al. (2012)

Donauer et al. (2012)

Valente et al. (2012)

McFarland et al. 2012

Ying et al. (2012)

Sun et al. (2012)

Komoike et al. (2012)

Zhao et al. (2012) 


\section{References}

Alster O, Bielak-Zmijewska A, Mosieniak G et al (2014) The role of nibrin in doxorubicin-induced apoptosis and cell senescence in Nijmegen Breakage Syndrome patients lymphocytes. PLoS ONE 9(8):e104964. doi:10.1371/journal.pone.0104964. eCollection 2014

Ambrosio G, Zweier JL, Duilio C et al (1993) Evidence that mitochondrial respiration is a source of potentially toxic oxygen free radicals in intact rabbit hearts subjected to ischemia and reflow. Biol Chem 268(25):18532-18541

An L, Wang X, Cederbaum AI (2012) Cytokines in alcoholic liver disease. Arch Toxicol 86(9):1337-1348. doi:10.1007/s00204012-0814-6

Aoki H, Kang PM, Hampe J et al (2002) Direct activation of mitochondrial apoptosis machinery by c-Jun N-terminal kinase in adult cardiac myocytes. J Biol Chem 277(12):10244-10250

Ashkenazi A, Dixit VM (1998) Death receptors: signaling and modulation. Science 281(5381):1305-1308 (Review)

Balmer NV, Klima S, Rempel E et al (2014) From transient transcriptome responses to disturbed neurodevelopment: role of histone acetylation and methylation as epigenetic switch between reversible and irreversible drug effects. Arch Toxicol 88(7):1451-1468. doi:10.1007/s00204-014-1279-6

Barnhart BC, Alappat EC, Peter ME (2003) The CD95 type I/type II model. Semin Immunol 15(3):185-193

Bezler M, Hengstler JG, Ullrich A (2012) Inhibition of doxorubicininduced HER3-PI3K-AKT signalling enhances apoptosis of ovarian cancer cells. Mol Oncol 6(5):516-529. doi:10.1016/j. molonc.2012.07.001

Chang HT, Chen IL, Chou CT et al (2013) Effect of caffeic acid on $\mathrm{Ca}(2+)$ homeostasis and apoptosis in SCM1 human gastric cancer cells. Arch Toxicol 87(12):2141-2150. doi:10.1007/ s00204-013-1075-8

Chen YW, Yang YT, Hung DZ et al (2012) Paraquat induces lung alveolar epithelial cell apoptosis via Nrf-2-regulated mitochondrial dysfunction and ER stress. Arch Toxicol 86(10):1547-1558. doi:10.1007/s00204-012-0873-8

Chio CC, Lin JW, Cheng HA et al (2013) MicroRNA-210 targets anti-apoptotic Bcl-2 expression and mediates hypoxia-induced apoptosis of neuroblastoma cells. Arch Toxicol 87(3):459-468. doi:10.1007/s00204-012-0965-5

D’Emilio A, Biagiotti L, Burattini S et al (2010) Morphological and biochemical patterns in skeletal muscle apoptosis. Histol Histopathol 25(1):21-32

Dias da Silva D, Carmo H, Lynch A et al (2013) An insight into the hepatocellular death induced by amphetamines, individually and in combination: the involvement of necrosis and apoptosis. Arch Toxicol 87(12):2165-2185. doi:10.1007/s00204-013-1082-9

Donauer J, Schreck I, Liebel U et al (2012) Role and interaction of p53, BAX and the stress-activated protein kinases p38 and JNK in benzo(a)pyrene-diolepoxide induced apoptosis in human colon carcinoma cells. Arch Toxicol 86(2):329-337. doi:10.1007/ s00204-011-0757-3

Escobar-García DM, Del Razo LM, Sanchez-Peña LC et al (2012) Association of glutathione S-transferase $\Omega$ 1-1 polymorphisms (A140D and E208 K) with the expression of interleukin-8 (IL8 ), transforming growth factor beta (TGF- $\beta$ ), and apoptotic protease-activating factor 1 (Apaf-1) in humans chronically exposed to arsenic in drinking water. Arch Toxicol 86(6):857-868. doi:10.1007/s00204-012-0802-x

Gabai VL, Yaglom JA, Volloch V et al (2000) Hsp72-mediated suppression of c-Jun $\mathrm{N}$-terminal kinase is implicated in development of tolerance to caspase-independent cell death. Mol Cell Biol 20(18):6826-6836
Galán A, García-Bermejo L, Troyano A et al (2001) The role of intracellular oxidation in death induction (apoptosis and necrosis) in human promonocytic cells treated with stress inducers (cadmium, heat, X-rays). Eur J Cell Biol 80(4):312-320

Gao M, Cheung KL, Lau IP et al (2012) Polyphyllin D induces apoptosis in human erythrocytes through $\mathrm{Ca}^{2+}$ rise and membrane permeabilization. Arch Toxicol 86(5):741-752. doi:10.1007/ s00204-012-0808-4

Godoy P, Hengstler JG, Ilkavets I et al (2009) Extracellular matrix modulates sensitivity of hepatocytes to fibroblastoid dedifferentiation and transforming growth factor beta-induced apoptosis. Hepatology 49(6):2031-2043

Godoy P, Hewitt NJ, Albrecht U et al (2013) Recent advances in 2D and $3 \mathrm{D}$ in vitro systems using primary hepatocytes, alternative hepatocyte sources and non-parenchymal liver cells and their use in investigating mechanisms of hepatotoxicity, cell signaling and ADME. Arch Toxicol 87(8):1315-1530. doi:10.1007/s00204013-1078-5.Review

Hammad S, Hoehme S, Friebel A et al (2014) Protocols for staining of bile canalicular and sinusoidal networks of human, mouse and pig livers, three-dimensional reconstruction and quantification of tissue microarchitecture by image processing and analysis. Arch Toxicol 88:1161-1183

Hanzel CE, Gubiani MFA, Verstraeten SV (2012) Endosomes and lysosomes are involved in early steps of Tl(III)-mediated apoptosis in rat pheochromocytoma (PC12) cells. Arch Toxicol 86(11):1667-1680. doi:10.1007/s00204-012-0878-3

Hour MJ, Lee KT, Wu YC et al (2013) A novel antitubulin agent, DPQZ, induces cell apoptosis in human oral cancer cells through Ras/Raf inhibition and MAP kinases activation. Arch Toxicol 87(5):835-846. doi:10.1007/s00204-012-0991-3

Hsieh MJ, Tsai TL, Hsieh YS et al (2013) Dioscin-induced autophagy mitigates cell apoptosis through modulation of PI3K/Akt and ERK and JNK signaling pathways in human lung cancer cell lines. Arch Toxicol 87(11):1927-1937. doi:10.1007/ s00204-013-1047-z

Ilowski M, Kleespies A, de Toni EN et al (2011) Augmenter of liver regeneration (ALR) protects human hepatocytes against apoptosis. Biochem Biophys Res Commun 404(1):148-152

Indran IR, Tufo G, Pervaiz S et al (2011) Recent advances in apoptosis, mitochondria and drug resistance in cancer cells. Biochim Biophys Acta 1807(6):735-745. doi:10.1016/ j.bbabio.2011.03.010.Review

Ivanova D, Gronemeyer H, Steinberg P et al (2013) Enantioselective apoptosis induction in histiocytic lymphoma cells and acute promyelocytic leukemia cells. Arch Toxicol 87(2):303-310. doi:10.1007/s00204-012-0930-3

Jazirehi AR, Baritaki S, Koya RC et al (2011) Molecular mechanism of MART-1 +/A*0201 + human melanoma resistance to specific CTL-killing despite functional tumor-CTL interaction. Cancer Res 71(4):1406-1417. doi:10.1158/0008-5472.CAN-10-1296

Jiang S, Cai J, Wallace DC et al (1999) Cytochrome c-mediated apoptosis in cells lacking mitochondrial DNA. Signaling pathway involving release and caspase 3 activation is conserved. J Biol Chem 274(42):29905-29911

Jilani K, Lang F (2013) Ca(2 +)-dependent suicidal erythrocyte death following zearalenone exposure. Arch Toxicol 87(10):18211828. doi:10.1007/s00204-013-1037-1

Komoike Y, Inamura H, Matsuoka M (2012) Effects of salubrinal on cadmium-induced apoptosis in HK-2 human renal proximal tubular cells. Arch Toxicol 86(1):37-44. doi:10.1007/s00204-011-0742-x

Krug AK, Kolde R, Gaspar JA et al (2013) Human embryonic stem cell-derived test systems for developmental neurotoxicity: a transcriptomics approach. Arch Toxicol 87(1):123-143. doi:10.1007/ s00204-012-0967-3 
Kunwar A, Jayakumar S, Srivastava AK et al (2012) Dimethoxycurcumin-induced cell death in human breast carcinoma MCF7 cells: evidence for pro-oxidant activity, mitochondrial dysfunction, and apoptosis. Arch Toxicol 86(4):603-614. doi:10.1007/ s00204-011-0786-y

Lee IC, Kim SH, Lee SM et al (2012) Melatonin attenuates gentamicin-induced nephrotoxicity and oxidative stress in rats. Arch Toxicol 86(10):1527-1536. doi:10.1007/s00204-012-0849-8

Li H, Wu S, Wang Z et al (2012a) Neuroprotective effects of tertbutylhydroquinone on paraquat-induced dopaminergic cell degeneration in C57BL/6 mice and in PC12 cells. Arch Toxicol 86(11):1729-1740. doi:10.1007/s00204-012-0935-y

Li Q, Kobayashi M, Kawada T (2012b) Mechanism of ziram-induced apoptosis in human T lymphocytes. Arch Toxicol 86(4):615-623. doi:10.1007/s00204-011-0791-1

Liu Q, Dong HW, Sun WG et al (2013) Apoptosis initiation of $\beta$-ionone in SGC-7901 gastric carcinoma cancer cells via a PI3K-AKT pathway. Arch Toxicol 87(3):481-490. doi:10.1007/ s00204-012-0962-8

Lopez M, Kopec AK, Joshi N et al (2014) Fas-induced apoptosis increases hepatocyte tissue factor procoagulant activity in vitro and in vivo. Toxicol Sci 141(2):453-464. doi:10.1093/toxsci/ kfu139

Matés JM, Segura JA, Alonso FJ et al (2008) Intracellular redox status and oxidative stress: implications for cell proliferation, apoptosis, and carcinogenesis. Arch Toxicol 82(5):273-299. doi:10.1007/ s00204-008-0304-z

Matés JM, Segura JA, Alonso FJ et al (2012) Oxidative stress in apoptosis and cancer: an update. Arch Toxicol 86(11):1649-1665. doi:10.1007/s00204-012-0906-3

McFarland AJ, Anoopkumar-Dukie S, Perkins AV et al (2012) Inhibition of autophagy by 3-methyladenine protects $1321 \mathrm{~N} 1$ astrocytoma cells against pyocyanin- and 1-hydroxyphenazineinduced toxicity. Arch Toxicol 86(2):275-284. doi:10.1007/ s00204-011-0755-5

Morita K, Saitoh M, Tobiume K et al (2001) Negative feedback regulation of ASK1 by protein phosphatase 5 (PP5) in response to oxidative stress. EMBO J 20(21):6028-6036

Nussler AK, Wildemann B, Freude T et al (2014) Chronic CCl4 intoxication causes liver and bone damage similar to the human pathology of hepatic osteodystrophy: a mouse model to analyse the liver-bone axis. Arch Toxicol 88:997-1006. doi:10.1007/ s00204-013-1191-5

Qing Y, Liang Y, Du Q et al (2013) Apoptosis induced by trimethyltin chloride in human neuroblastoma cells SY5Y is regulated by a balance and cross-talk between NF-кB and MAPKs signaling pathways. Arch Toxicol 87(7):1273-1285. doi:10.1007/ s00204-013-1021-9

Schreck I, Deigendesch U, Burkhardt B et al (2012) The Alternaria mycotoxins alternariol and alternariol methyl ether induce cytochrome P450 1A1 and apoptosis in murine hepatoma cells dependent on the aryl hydrocarbon receptor. Arch Toxicol 86(4):625-632. doi:10.1007/s00204-011-0781-3

Sinha K, Das J, Pal PB et al (2013) Oxidative stress: the mitochondriadependent and mitochondria-independent pathways of apoptosis. Arch Toxicol 87(7):1157-1180. doi:10.1007/s00204-013-1034-4

Sisnaiske J, Hausherr V, Krug AK et al (2014) Acrylamide alters neurotransmitter induced calcium responses in murine ESCderived and primary neurons. Neurotoxicology 43:117-126. doi:10.1016/j.neuro.2014.03.010

Sun Y, Lin Y, Li H et al (2012) 2,5-Hexanedione induces human ovarian granulosa cell apoptosis through BCL-2, BAX, and
CASPASE-3 signaling pathways. Arch Toxicol 86(2):205-215. doi:10.1007/s00204-011-0745-7

Swarnkar S, Goswami P, Kamat PK et al (2012) Rotenone-induced apoptosis and role of calcium: a study on Neuro-2a cells. Arch Toxicol 86(9):1387-1397. doi:10.1007/s00204-012-0853-z

Thévenod F, Lee WK (2013) Cadmium and cellular signaling cascades: interactions between cell death and survival pathways. Arch Toxicol 87(10):1743-1786. doi:10.1007/s00204-013-1110-9

Valente MJ, Henrique R, Vilas-Boas V et al (2012) Cocaine-induced kidney toxicity: an in vitro study using primary cultured human proximal tubular epithelial cells. Arch Toxicol 86(2):249-261. doi:10.1007/s00204-011-0749-3

van Thriel C, Westerink RH, Beste C et al (2012) Translating neurobehavioural endpoints of developmental neurotoxicity tests into in vitro assays and readouts. Neurotoxicology 33(4):911-924. doi:10.1016/j.neuro.2011.10.002

Waldmann T, Rempel E, Balmer NV et al (2014) Design principles of concentration-dependent transcriptome deviations in drugexposed differentiating stem cells. Chem Res Toxicol 27(3):408420. doi:10.1021/tx400402j

Weng MK, Natarajan K, Scholz D et al (2014) Lineage-specific regulation of epigenetic modifier genes in human liver and brain. PLoS ONE 9(7):e102035. doi:10.1371/journal.pone.0102035

Wyllie AH (2010) "Where, O death, is thy sting?" A brief review of apoptosis biology. Mol Neurobiol 42(1):4-9. doi:10.1007/ s12035-010-8125-5.Review

Xiong S, George S, Yu H et al (2013) Size influences the cytotoxicity of poly (lactic-co-glycolic acid) (PLGA) and titanium dioxide (TiO(2)) nanoparticles. Arch Toxicol 87(6):1075-1086. doi:10.1007/s00204-012-0938-8

Xu J, Li Z, Xu P et al (2013a) Nanosized copper oxide induces apoptosis through oxidative stress in podocytes. Arch Toxicol 87(6): 1067-1073. doi:10.1007/s00204-012-0925-0

Xu S, Zhang YF, Carew MW et al (2013b) Multidrug resistance protein 1 (ABCC1) confers resistance to arsenic compounds in human myeloid leukemic HL-60 cells. Arch Toxicol 87(6):10131023. doi:10.1007/s00204-012-0956-6

Yajima I, Uemura N, Nizam S et al (2012) Barium inhibits arsenicmediated apoptotic cell death in human squamous cell carcinoma cells. Arch Toxicol 86(6):961-973. doi:10.1007/s00204-012-0848-9

Yen YP, Tsai KS, Chen YW et al (2012) Arsenic induces apoptosis in myoblasts through a reactive oxygen species-induced endoplasmic reticulum stress and mitochondrial dysfunction pathway. Arch Toxicol 86(6):923-933. doi:10.1007/s00204-012-0864-9

Ying TH, Yang SF, Tsai SJ et al (2012) Fisetin induces apoptosis in human cervical cancer HeLa cells through ERK1/2-mediated activation of caspase-8-/caspase-3-dependent pathway. Arch Toxicol 86(2):263-273. doi:10.1007/s00204-011-0754-6

Yoo BH, Wu X, Derouet M et al (2009) Hypoxia-induced downregulation of autophagy mediator Beclin 1 reduces the susceptibility of malignant intestinal epithelial cells to hypoxia-dependent apoptosis. Autophagy 5(8):1166-1179

Zhao H, Cheng J, Cai J et al (2012) Liver injury and its molecular mechanisms in mice caused by exposure to cerium chloride. Arch Environ Contam Toxicol 62(1):154-164. doi:10.1007/ s00244-011-9672-0

Zhao X, Ng S, Heng BC et al (2013) Cytotoxicity of hydroxyapatite nanoparticles is shape and cell dependent. Arch Toxicol 87(6):1037-1052. doi:10.1007/s00204-012-0827-1 